\title{
Tênue equilíbrio: a vida de pessoas escravizadas no Brasil oitocentista
}

A Tenuous Balance: The Life of Enslaved People in Nineteenth-Century Brazil

Hilton Costa*

PEDROSO, Wagner de Azevedo. Nazário e um plano de rebelião escrava na Aldeia dos Anjos: "os brancos eram uns pelos outros, por isso os negros também deviam fazer o mesmo". Porto Alegre: Coragem, 2020. 168 p.

\begin{abstract}
Nas Américas, em particular, a escravidão na grande lavoura foi ao mesmo tempo um sistema de trabalho, um modo de dominação racial e a base para o surgimento de uma classe dominante bem caracterizada (Foner, 1988, p. 17).
\end{abstract}

A assertiva de Eric Foner presente na introdução da ainda pertinente obra Nada além da liberdade parece ser das mais adequadas para iniciarmos a presente discussão acerca do livro Nazário e um plano de rebelião escrava na Aldeia dos Anjos. Wagner de Azevedo Pedroso está inscrito em um grupo maior de pesquisadores e pesquisadoras que há pelo menos vinte anos vem produzindo, nos diferentes espaços de pesquisa do Rio Grande do Sul, um substancial trabalho acerca da região à época do escravismo e logo após o seu término. A reflexão proposta por Pedroso está inserida no contexto de produção de obras como, por exemplo, a de Thiago Leitão de Araújo, Escravidão, fronteira e liberdade: políticas de domínio, trabalho e luta em um contexto produtivo agropecuário (Vila da Cruz Alta, Província do Rio Grande de São Pedro, 1834-1884) (2008), a de Vinicius Pereira de Oliveira, A presença negra no porto de Rio Grande (2009), a de Gabriel Santos Berute, Dos escravos que partem para os portos do sul: características do tráfico negreiro do Rio Grande de São Pedro do Sul, c. 1790-c.1825 (2006), a de Melina Kleinert Perussatto, Arautos da liberda-

\footnotetext{
* Universidade Estadual de Maringá (UEM), Maringá, PR, Brasil. hcosta@uem.br <https://orcid. org/0000-0002-2140-7729>
} 
de: educação, trabalho e cidadania no pós-abolição a partir do jornal O Exemplo de Porto Alegre (c.1892-c.1911) (2013), a de Rodrigo de Azevedo Weimer, Os nomes da liberdade: experiências de autonomia e práticas de nomeação em um município da serra rio-grandense nas duas últimas décadas do século XIX (2007) e a de Fernanda Oliveira Silva, Os negros, a constituição de espaços para os seus e o entrelaçamento desses espaços: associações e identidades negras em Pelotas (1820-1943) (2011). Trabalhos estes, em grande medida, aglutinados em torno do GT Emancipações e Pós-Abolição da Associação Nacional de História (GTEP/ANPUH), do GT Emancipação e Pós-Abolição da ANPUH-RS e dos encontros “Escravidão e Liberdade no Brasil Meridional”, vinculado ao Grupo de Pesquisa do CNPq, e "A experiência dos africanos e seus descendentes no Brasil".

A perspectiva que aproxima estes diferentes trabalhos e vários outros produzidos neste ambiente, segundo se entende aqui, é a compreensão da agência das pessoas escravizadas, considerando-se as formas ativas como elas atuavam sobre seus destinos em um contexto muito pouco favorável. Um último e pertinente exemplo deste cenário intelectual é a obra Pessoas comuns, Histórias incríveis (2017), texto coletivo produzido por Fernanda Oliveira da Silva, Jardélia Rodrigues de Sá, Luciano Costa Gomes, Marcus Vinicius de Freitas Rosa, Melina Kleinert Perussato, Sarah Calvi Amaral Silva e Sherol dos Santos, voltado ao grande público, notadamente o escolar, que traz a lume outra história do Rio Grande do Sul a partir da perspectiva de pessoas negras, evidenciando a já mencionada busca pela compreensão da atuação, em um cenário quase sempre adverso, tanto das pessoas escravizadas quando da população negra após o término do escravismo.

O trabalho de Pedroso dialoga com a obra de Hebe Mattos Das cores do silêncio (1998) e com as produções de Paulo Roberto Staudt Moreira Sobre fronteira e liberdade (1998), Os cativos e os homens de bem (2003), Entre o deboche e a rapina (2009). As obras de Helen Osório, Fronteira, escravidão e pecuária (2005), e de Regina Célia Lima Xavier, A conquista da liberdade (1996) e Religiosidade e escravidão, século XIX (2008), também são mobilizadas com destaque pelo autor. Um dos pontos centrais de sua discussão é a problematização da agência das pessoas escravizadas. O seu esforço de compreender como as pessoas escravizadas "jogavam” um "jogo" cujas regras lhes eram consideravelmente desfavoráveis se estabelece a partir de um uso profícuo, sobretudo, das considerações de Eduardo Silva e João José Reis expressas em Negociação e conflito (1989), como se verá adiante.

Pedroso traz a lume, em Nazário e um plano de rebelião escrava na Aldeia 
dos Anjos, discussões resultantes de sua dissertação de mestrado, defendida em 2013 no Programa de Pós-Graduação em História da Universidade Federal do Rio Grande do Sul, sob o título de Escravos, senhores, posses, partilhas e um plano insurrecional da Freguesia de Nossa Senhora da Aldeia dos Anjos, RS (1863).

Nazário e um plano de rebelião escrava na Aldeia dos Anjos conta com um prefácio assinado por Regina Célia Lima Xavier. Das considerações de Xavier destaca-se aqui a sua observação acerca de como a pesquisa de Pedroso traz algo relativamente inovador nas pesquisas sobre as insurreições do período: a predominância de pessoas escravizadas nascidas no Brasil envolvidas com uma revolta ou tentativa de revolta. A revolta e/ou a tentativa de revolta de pessoas escravizadas na primeira metade do século XIX, com a predominância de pessoas nascidas no Brasil, é um elemento de certa novidade, pois as investigações sobre o período revelam alta taxa de africanidade nas insurreições então ocorridas. O livro está organizado em três capítulos. O primeiro, denominado "Entre conversas e caminhadas: os escravizados e a Aldeia dos Anjos", é dedicado a investigar a divulgação do plano de insurgência, denotando a articulação e a mobilidade da comunidade de pessoas escravizadas no contexto da Freguesia de Nossa Senhora da Aldeia dos Anjos, uma localidade que produzia para o mercado interno, detentora de escravarias relativamente pequenas (em comparação, por exemplo, com a produção cafeeira do Sudeste), empregadas em um rol bastante vasto de atividades.

Já o segundo capítulo, "Entre senhores e escravizados: os senhores moços e a força do sistema escravista”, concentra-se nos objetivos da rebelião. Neste capítulo, o rico entrecruzamento de fontes permite visualizar as alterações na forma de dominação e a entrada dos padrões de controle dos senhores moços. As páginas do segundo capítulo trazem a possibilidade de melhor compreendermos a imbricada teia de relações sociais da camada senhorial da região, bem como de percebermos como essas relações, apesar, evidentemente, das particularidades regionais, estavam articuladas à realidade maior do Império. Assim, as alterações na dinâmica imperial a partir, sobretudo, da década de 1850, tiveram implicações sobre a camada senhorial, e as modificações na camada senhorial trouxeram mudanças para a vida das pessoas escravizadas. $\mathrm{O}$ terceiro capítulo, "Entre a escravidão e a liberdade: da delação ao retorno ao cotidiano", tem como foco acompanhar o destino das pessoas envolvidas com a elaboração da tentativa de revolta após o seu malogro. Da repressão senhorial ao retorno às rotinas de um determinado cotidiano, o capítulo revela o tênue equilíbrio construído sobre a base da negociação e do conflito. 
Pedroso menciona, no início da sua obra, o quanto o livro de Carlo Ginzburg O queijo e os vermes (1987) foi importante para motivá-lo a ir ao arquivo pesquisar e encontrar o seu Menocchio. Em suas buscas no Arquivo Público do Rio Grande do Sul, o autor não encontrou um Menocchio, todavia, ele encontrou o processo-crime de uma tentativa de insurreição de pessoas escravizadas na Freguesia de Nossa Senhora da Aldeia dos Anjos, a qual se localizava entre os atuais territórios dos municípios de Viamão e Gravataí. Charles Sidarta Machado Domingos, na contracapa, localiza tal freguesia no atual território de Gravataí. De fato, até onde se sabe, houve alterações no limite territorial da Aldeia dos Anjos ao longo do tempo, de modo a ser viável pensar que ambas as informações sobre a localização da freguesia são plausíveis.

Se Pedroso teve sua inspiração inicial em Ginzburg, aqui ela vem de Foner, uma vez que, ao se ler Nazário e um plano de rebelião escrava na Aldeia dos Anjos, é possível localizarmos muito mais que uma tentativa "de uma revolta" da mão de obra escravizada. Encontra-se no texto um relato fundamental sobre as transições econômicas e sociais do Brasil imperial na década de 1860. Destaca-se a alteração na forma de dominação escravocrata dos denominados "senhores moços" em relação aos antigos senhores. Os primeiros, devido às alterações no fluxo de pessoas escravizadas -oferta de mão de obra que diminui -, passaram a ter que extrair muito mais de suas escravarias, em comparação com os senhores antigos. Desta forma, "direitos costumeiros" das pessoas escravizadas passam a ser revogados. Em regiões como a da Freguesia de Nossa Senhora da Aldeia dos Anjos, essas mudanças sócio-econômicas resultam em uma grande quantidade de pessoas escravizadas em uma área espacial relativamente reduzida.

Esta grande concentração de pessoas escravizadas resultou, segundo a análise de Pedroso, em um contingente de pessoas aparentadas. Somando-se a isso a mobilidade desses indivíduos, característica importante das escravarias da região - aspecto também destacado pelo autor -, tem-se uma comunidade muito bem articulada. A constatação concernente à articulação das pessoas escravizadas já não causa espanto na comunidade de pesquisadoras e pesquisadores desde muito tempo. Todavia, fora dela isso ainda é algo "novo". O fato de a comunidade ser bastante aparentada revela também traços de uma reprodução endógena; ou seja, toda essa gente é, em sua maioria, nascida no Brasil.

Pedroso indica com perspicácia em seu texto que, se há uma articulação forte entre as pessoas escravizadas, o mesmo se dá nas camadas senhoriais. Os senhores moços sabem que, devido ao fim do tráfico internacional, a oferta de mão de obra escravizada diminuíra, reduzindo-se ao mercado interno; e neste, 
os proprietários e as proprietárias de pessoas escravizadas do Rio Grande do Sul não tinham recursos para competir com as demandas do Sudeste. Assim, restava à camada senhorial rio-grandense, de modo geral, manter as suas escravarias e, se possível, fazê-las se reproduzirem endogenamente. Estas situações levam os senhores moços a praticarem outras formas de dominação em comparação, por exemplo, com seus pais.

Esta "nova" dominação, ou esse outro tipo de dominação, cria tensões enormes no equilíbrio tênue da sociedade escravocrata brasileira e rio-grandense. Neste ponto da argumentação proposta por Pedroso fica nítida a utilização profícua e aguçada das sugestões e considerações de Eduardo Silva e João José Reis, presentes no clássico moderno Negociação e conflito. Existe uma máxima segundo a qual só possível burlarem-se as regras quando se tem domínio das mesmas. É difícil passar pelas páginas de Nazário e um plano de rebelião escrava na Aldeia dos Anjos sem que essa máxima emerja. Tomada em conjunto com as considerações de Silva e Reis, esta máxima convida-nos a pensar que a comunidade de pessoas escravizadas possuía o domínio das regras de negociação e conflito dentro do padrão de dominação dos senhores velhos. Tais pessoas, mesmo em condições de jogo muito desiguais, sabiam como jogar, como se posicionar. Entretanto, a transição para um novo tipo de dominação traz novas regras, retira destas pessoas o "domínio" que possuíam dos mecanismos que regiam suas existências. Uma resposta a isso seria a revolta.

Se o ambiente é de negociação e conflito, a revolta das pessoas escravizadas, ao contrário de uma primeira impressão, podia visar não a conquista a liberdade, mas sim a manutenção de determinado padrão nas relações de dominação. Não parece ser exagero, muito menos descabido, lembrarmos que, para se fugir - sobretudo no período escravocrata -, era preciso saber para onde, caso contrário, fugir não seria uma alternativa. Os insurgentes da Freguesia de Nossa Senhora da Aldeia dos Anjos não tinham na fuga uma ideia mote: a ideia mote parecia ser mesmo a de alcançar a liberdade. Mas, a liberdade onde? Na própria região? Como o plano de insurgência malogrou, a fuga surgiu como uma opção para os revoltosos. No entanto, fuga para onde? Para a fronteira. A fronteira representava um ideário relevante de liberdade neste contexto, pois, à época, tanto as Províncias Unidas (atual Argentina) quanto a Banda Oriental (atual Uruguai) tinham abolido a escravidão. Contudo, essa fuga era de fato impossível, pois se tratava de viajar cerca de 500 quilômetros no mundo escravocrata na condição de escravo fugido. Desta forma, outra maneira de os insurgentes reagirem ao malogro da revolta foi a tentativa de recorrerem ao apadrinhamento. 
Pedroso, ao discutir o apadrinhamento como uma alternativa, traz muitos elementos de como se efetivava a sociabilidade neste ambiente. Visando a diminuição das punições pela tentativa de insurgência, buscava-se o apadrinhamento; recorria-se a um senhor ou a uma senhora para que esta pessoa da camada senhorial interviesse em favor da pessoa escravizada. As perguntas imediatas ao nos depararmos com tal situação são: porque um senhor ou uma senhora fariam isso? E por que uma pessoa escravizada procuraria a ajuda das pessoas que seriam os alvos da sua revolta?

O equilíbrio tênue de regiões como a Freguesia de Nossa Senhora da Aldeia dos Anjos permite pensarmos que as pessoas escravizadas possuíam bastante nitidez de seu valor e importância para o funcionamento da região. Com escravarias compostas em média por quatro a cinco pessoas, como Pedroso indica no que diz respeito à região em questão, pode-se pensar que as duas pontas chegavam, por caminhos diferentes, a conclusões semelhantes: executar, aprisionar ou inutilizar para o trabalho uma pessoa escravizada era um prejuízo insuperável. É válido focarmos em outra informação muito relevante trazida por Pedroso: ao analisar os inventários post-mortem, ele percebe que, para muitos senhores e senhoras da região, seu "bem" de maior valor eram as pessoas escravizadas. Se a hipótese aqui esposada estiver minimamente correta, as regras do jogo eram conhecidas por todas as pessoas. Desta forma, buscar apadrinhamento era uma opção das mais válidas. Como as regras deste jogo de tênue equilíbrio eram de conhecimento comum, torna-se válido mencionarmos que era de conhecimento das pessoas escravizadas que, após uma tentativa de insurreição, viriam punições. Assim, estava em jogo não a ausência de punição, mas sim o seu tipo. Pedroso enfatiza que a punição pela tentativa de insurreição recaiu sobre toda a comunidade de pessoas escravizadas, muito provavelmente até sobre quem delatou os planos de revolta.

O resultado da tentativa de insurreição é conhecido desde o começo do texto: as lideranças foram presas e julgadas, com exceção daquelas que morreram no confronto com as "autoridades"; caso de Nazário, tomado como o grande elaborador e articulador da ação, como se pode verificar no processo-crime contra os insurretos. No que concerne ao processo-crime, podemos destacar outro aspecto essencial da obra Nazário e um plano de rebelião escrava na Aldeia dos Anjos: o cruzamento de diferentes tipos de fontes - além dos processos-crimes, inventários, listas nominais de nascimento, casamento, batismo, morte. Manuscritos que não foram de forma alguma produzidos para a historiadora, para o historiador. A pessoa que se encanta com o ofício de historiar 
tem que conversar com essa documentação - uma conversa crítica, dura, rígida.

A elaboração de Nazário e um plano de rebelião escrava na Aldeia dos Anjos, além de contar com um trabalho bastante relevante de cruzamento de fontes, também apresenta um uso muito criativo da bibliografia recente produzida sobre o tema. O diálogo do autor com a produção recente indica o quão profícuo vem sendo o já citado grupo de pesquisadores e pesquisadoras que, como também já mencionado, vem, há pelo menos vinte anos, produzindo trabalhos fundamentais para um melhor entendimento do Brasil sob o regime escravista, bem como sobre a forma como o país se organizou nos primeiros momentos pós-escravismo. No que diz respeito à colaboração desta obra para um melhor entendimento do Brasil escravista, é importante mencionarmos que ainda é comum, de modo mais amplo, as pessoas associarem a escravidão à grande lavoura, à monocultura voltada à exportação; de certo modo, uma leitura menos atenta da epígrafe selecionada para este texto poderia, inclusive, colaborar para essa impressão. Contudo, a obra Nazário e um plano de rebelião escrava na Aldeia dos Anjos demonstra justamente a importância das pessoas escravizadas na dinâmica de um mercado interno, na produção de itens voltados ao consumo na própria região - atividade esta que produzia certa riqueza, evidentemente não a mesma riqueza dos cafeicultores do Sudeste, mas que não era, de forma alguma, irrelevante. Assim, o texto de Pedroso está alinhado à produção historiográfica disposta a rever algumas "verdades" intocáveis sobre os padrões de riqueza no Brasil imperial, bem como sobre as dinâmicas do mercado interno.

Este texto se encerra com argumentos acerca da edição de Nazário e um plano de rebelião escrava na Aldeia dos Anjos. Almejando, segundo compreendemos, atingir um público tanto de especialistas quanto de não especialistas, a obra conta com uma diagramação bastante oportuna, trazendo, em suas páginas, caixas explicativas de determinados termos, conceitos e eventos, bem como referenciando autoras e autores estudiosos do tema. Uma opção das mais felizes. Outra opção acertada foi a mencionada logo no início desta argumentação: de narrar fluidamente como funciona o ofício de historiar. A casa editorial que abriga a obra tem por nome Editora Coragem, fundada no ano 2020. Não poderia haver nome mais pertinente. Muito possivelmente foi a coragem, em várias de suas vertentes, que manteve todas as pessoas escravizadas na Freguesia de Nossa Senhora da Aldeia dos Anjos - como em todos os quase 400 anos de escravidão no Brasil - firmes e perseverantes, mesmo vivendo em um tênue equilíbrio. 


\section{REFERÊNCIAS}

ARAÚJO, Thiago Leitão de. Escravidão, fronteira e liberdade: políticas de domínio, trabalho e luta em um contexto produtivo agropecuário (Vila da Cruz Alta, Província do Rio Grande de São Pedro, 1834-1884). Dissertação (Mestrado em História) - Instituto de Filosofia e Ciências Humanas, Universidade Federal do Rio Grande do Sul. Porto Alegre, 2008.

BERUTE, Gabriel Santos. Dos escravos que partem para os portos do sul: características do tráfico negreiro do Rio Grande de São Pedro do Sul, c. 1790-c. 1825. Dissertação (Mestrado em História) - Instituto de Filosofia e Ciências Humanas, Universidade Federal do Rio Grande do Sul. Porto Alegre, 2006.

FONER, Eric. Nada além da liberdade: a emancipação e seu legado. Rio de Janeiro: Paz e Terra; Brasília: CNPq, 1988. 186 p.

GINZBURG, Carlo. O queijo e os vermes: o cotidiano e as idéias de um moleiro perseguido pela Inquisição. Tradução de Maria Betânia Amoroso. São Paulo: Companhia das Letras, 1987. 274 p.

MATTOS, Hebe Maria. Das cores do silêncio: os significados da liberdade no sudeste escravista, Brasil século XIX. Rio de Janeiro: Nova Fronteira, 1998.

MOREIRA, Paulo Roberto Staudt. Sobre fronteira e liberdade - representações e práticas dos escravos gaúchos na Guerra do Paraguai (1864-1870). Anos 90, Porto Alegre, v. 6, n. 9, pp. 119-149, jul. 1998.

MOREIRA, Paulo Roberto Staudt. Os cativos e os homens de bem: experiências negras no espaço urbano. Porto Alegre 1858-1888. Porto Alegre: EST Edições, 2003.

MOREIRA, Paulo Roberto Staudt. Entre o deboche e a rapina: os cenários sociais da criminalidade popular em Porto Alegre. Porto Alegre: Armazém Digital, 2009.

OLIVEIRA, Vinicius Pereira de. A presença negra no porto de Rio Grande. Tese (Doutorado em História) - Programa de Pós-Graduação em História, Universidade Federal do Rio Grande do Sul. Porto Alegre, 2009.

OSÓRIO, Helen. Fronteira, escravidão e pecuária: Rio Grande do Sul no período colonial. JORNADAS DE HISTÓRIA REGIONAL COMPARADA, II. In: TARGA, Luiz Roberto; HERRLEIN JÚNIOR, Ronaldo; MERTZ, Marli Marlene (Orgs.). Anais: II Jornadas de História Regional Comparada; I Jornadas de Economia Regional Comparada. Porto Alegre: PUC-RS, 2005. pp. 1-16.

PEDROSO, Wagner de Azevedo. Nazário e um plano de rebelião escrava na Aldeia dos Anjos: "os brancos eram uns pelos outros, por isso os negros também deviam fazer o mesmo". Porto Alegre: Coragem, 2020. 168 p.

PERUSSATTO, Melina Kleinert. Arautos da liberdade: educação, trabalho e cidadania no pós-abolição a partir do jornal O Exemplo de Porto Alegre (c.1892-c.1911) Dissertação (Mestrado em História) - Instituto de Filosofia e Ciências Humanas, Universidade Federal do Rio Grande do Sul. Porto Alegre, 2013. 
REIS, João José; SILVA, Eduardo. Negociação e conflito: a resistência negra no Brasil escravista. São Paulo: Companhia das Letras, 1989. 154 p.

SILVA, Fernanda Oliveira da et al. Pessoas comuns, histórias incríveis: a construção da liberdade na sociedade sul-rio-grandense. Porto Alegre: Ed. UFRGS; EST Edições, 2017. 112p.

SILVA, Fernanda Oliveira da. Os negros, a constituição de espaços para os seus e o entrelaçamento desses espaços: associações e identidades negras em Pelotas (1820-1943). Dissertação (Mestrado em História) - Faculdade De Filosofia e Ciências Humanas, Pontifícia Universidade Católica do Rio Grande do Sul. Porto Alegre, 2011.

XAVIER, Regina Célia Lima. A conquista da liberdade: libertos em Campinas na segunda metade do século XIX. Campinas: Centro de Memória da Unicamp, 1996.

XAVIER, Regina Célia Lima. Religiosidade e escravidão, século XIX: mestre Tito. Porto Alegre: Editora da UFRGS, 2008.

WEIMER, Rodrigo de Azevedo. Os nomes da liberdade: experiências de autonomia e práticas de nomeação em um município da serra rio-grandense nas duas últimas décadas do século XIX. Dissertação (Mestrado em História) - Programa de Pós Graduação em História, Universidade do Vale do Rio dos Sinos. São Leopoldo, 2007.

Resenha submetida em 30 de março de 2021. Aprovada em 17 de novembro de 2021. 